\title{
Ultrasound guided supraclavicular block
}

\section{Deepak Hanumanthaiah, Sabanayagam Vaidiyanathan, Maria Garstka, Szilard Szucs, Gabriella Iohom}

Department of Anaesthesia and Intensive Care Medicine, Cork University Hospital and University College Cork, Ireland

\section{Abstract}

Ultrasound guided regional anaesthesia is becoming increasingly popular. The supraclavicular block has been transformed by ultrasound guidance into a potentially safe superficial block. We reviewed the techniques of performing supraclavicular block with special focus on ultrasound guidance.

Keywords: supraclavicular block, regional anaesthesia, ultrasound, complications

\section{Introduction}

With increasing emphasis on patient safety and better patient outcomes, ultrasound guided regional anaesthesia [UGRA] is becoming more and more popular. Ultrasound provides clinicians with a real time image useful for visualizing anatomical structures, needle placement and local anaesthetic spread. Supraclavicular brachial plexus block provides consistently effective anaesthesia to the upper extremity $[1,2]$. This review focuses on ultrasound guided supraclavicular block, which is currently undergoing a renaissance.

\section{Anatomy of supraclavicular brachial plexus}

The primary ventral rami of C5 and C6 unite near the medial border of the middle scalene muscle to form the superior trunk of the brachial plexus [2]. The $\mathrm{C} 7$ ramus becomes the middle trunk; and $\mathrm{C} 8$ and $\mathrm{T} 1$ rami unite

Received 08.06.2013 Accepted 20.06.2013

Med Ultrason

2013, Vol. 15, No 3, 224-229

Corresponding author: Gabriella Iohom MD, PhD

Department of Anaesthesia and Intensive

Care Medicine

Cork University Hospital and University

College Cork

Wilton Road, Cork, Ireland

Tel.: +35321 4922135, Fax: +353214546434

Email: gabriella.iohom@hse.ie to form the inferior trunk. Variable contributions may arise from $\mathrm{C} 4$ and $\mathrm{T} 2$. Both the brachial plexus and the subclavian artery lie on top of the first rib. The three trunks undergo division at the lateral border of the first rib. The anterior divisions of the superior and middle trunk form the lateral cord, the posterior divisions of all three trunks form the posterior cord and the anterior division of the inferior trunk forms the medial cord. Seven different configurations of the brachial plexus have been described [2]. In the supraclavicular fossa, the brachial plexus is located lateral and superficial to the subclavian artery. The subclavian vein and anterior scalene muscle are found medial to the subclavian artery. The pleura is usually found within 1-2 cm from the brachial plexus [3].

The supraclavicular block is performed at the distal trunk/proximal division level, where the brachial plexus is most compact. This may explain its historical reputation for providing fast onset and complete, reliable anaesthesia for the upper limb, and the nickname 'spinal of the arm'.

\section{Anatomical Landmark technique and Nerve Stimulation technique}

Initially described by Kulenkampff and Persy [4] in the early 20th century, the supraclavicular approach to the brachial plexus provides more consistent and effective regional anesthesia to the upper extremity than other 
approaches to brachial plexus blockade [5]. As originally described, this technique requires the insertion of a needle toward the first rib where the brachial plexus lies in close proximity to the subclavian artery. Many modifications of this technique have been developed [6,7]. The most important modification is the "plumb bob technique" [8]. In this technique the point of needle insertion is at the junction between the superior edge of the clavicle and the most lateral part of the sternocleidomastoid muscle. The needle direction is antero-posterior. If brachial plexus contact is not achieved by the initial needle pass, the needle may be redirected cephalad in small steps up to $20^{\circ}$ or $30^{\circ}$ and subsequently caudal up to $20^{\circ}$ or $30^{\circ}$, while staying in the sagittal plane through the initial needle entry site. All anatomical landmark methods used paraesthesia as a method of identification of the brachial plexus.

Localization of brachial plexus using nerve stimulator led to more effective and reliable blocks, but the risk of complications remained high [9].

Traditionally, supraclavicular blocks were associated with a high risk of complications including pneumothorax, phrenic nerve block, intravascular injections and Horner syndrome [7].

\section{Ultrasound guided supraclavicular block:}

Ultrasound guidance provides real time images, thereby in appropriately trained and experienced hands, has the potential to minimize the risk of complications.

The first literature description of the use of ultrasound for supraclavicular block was by La Grange and colleagues in 1978 for needle positioning [10]. Kapral et al were the first to report direct needle, plexus and local anaesthetic visualization. Using a $7.5 \mathrm{MHz}$ probe, orientated $3 \mathrm{~cm}$ sagittally above the midpoint of the clavicle, their success rate was $95 \%$ [11]. Chan et al is credited with popularizing the technique [12]. The placement of catheters for continuous supraclavicular nerve block was first described by Yang et al [13].

\section{Image acquisition}

After skin and transducer preparation, a linear 38$\mathrm{mm}$, high frequency $10-15 \mathrm{MHz}$ transducer is placed firmly over the supraclavicular fossa in the coronal oblique plane to obtain the best possible transverse view of the subclavian artery and brachial plexus. The patient is supine facing the contralateral side (fig 1). Nerves in the supraclavicular region appear hypo-echoic and are round or oval. The brachial plexus is located lateral and superficial to the pulsatile subclavian artery and superior to the first rib. The subclavian artery is identified

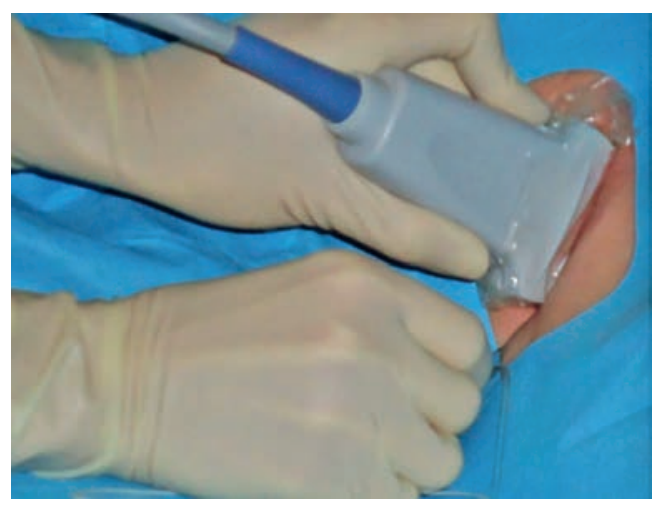

Fig 1. Apparatus and positioning of patient for UGSCB. Patient supine, head turned away; operator behind patient's head; probe parallel to the clavicle in the supraclavicular fossa; needle inserted from lateral to medial.

first (fig 2), the subclavian vein lies more medially. The first rib is identified as a hyper-echoic structure lying deep to the vessels, and giving a bony shadow (dropout). The brachial plexus is consistently found lateral and superficial to the subclavian artery and above the first rib (fig 3).

\section{Needling}

In plane approach (Lateral to medial). This is the recommended approach, as the subclavian artery may traverse the brachial plexus. Ultrasound is useful, as Doppler can be used to identify the vessels (fig 2). For the in plane approach, a $5 \mathrm{~cm} 22 \mathrm{G}$ insulated block needle is inserted under sterile conditions on the outer (lateral) end of the ultrasound transducer (5-12 or 6-13 MHz) after skin local anaesthetic infiltration. The brachial plexus is identified as a compact group of nerves, sometimes compared to 'a bunch of grapes', located over the first rib, lateral and superficial to the subclavian artery. The rib and pleura are identified before needle insertions. The needle is advanced along the long axis of the transducer in the same plane as the ultrasound beam (fig 3). This way, the needle shaft and tip can be visualized in real time as the needle is advanced towards the target nerves. The identity of the nerves may be confirmed by electrical stimulation if desired. Useful stimulation endpoints for surgery proximal to the elbow are biceps and triceps twitches; hand muscle twitches are more appropriate for surgery distal to the elbow. Local anaesthetic solution is injected so as to cause hydro dissection of the planes around the plexus (fig 4, fig 5). The volume of local anaesthestic used is usually between 25 to $40 \mathrm{ml}$.

In plane (medial to lateral) approach may also be used based on user comfort. 

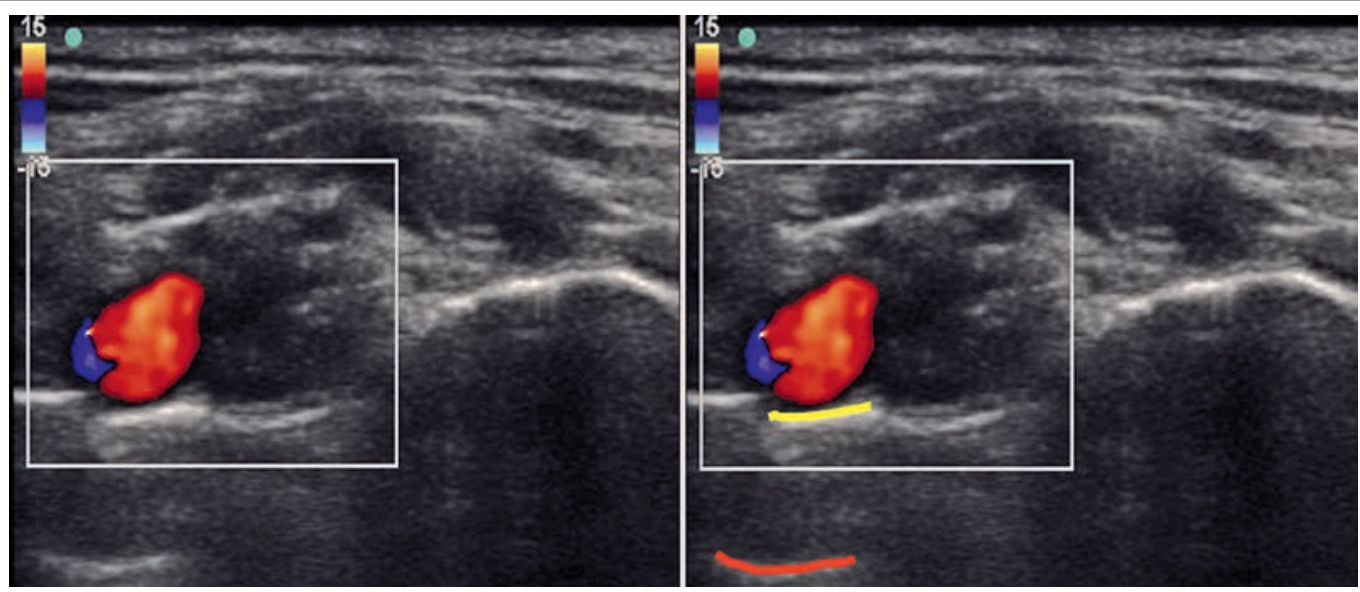

Fig 2. Doppler for identification of vessels. Indicated for both initial identification of subclavian vessels and aberrant vessels traversing the plexus before choosing the needle trajectory.

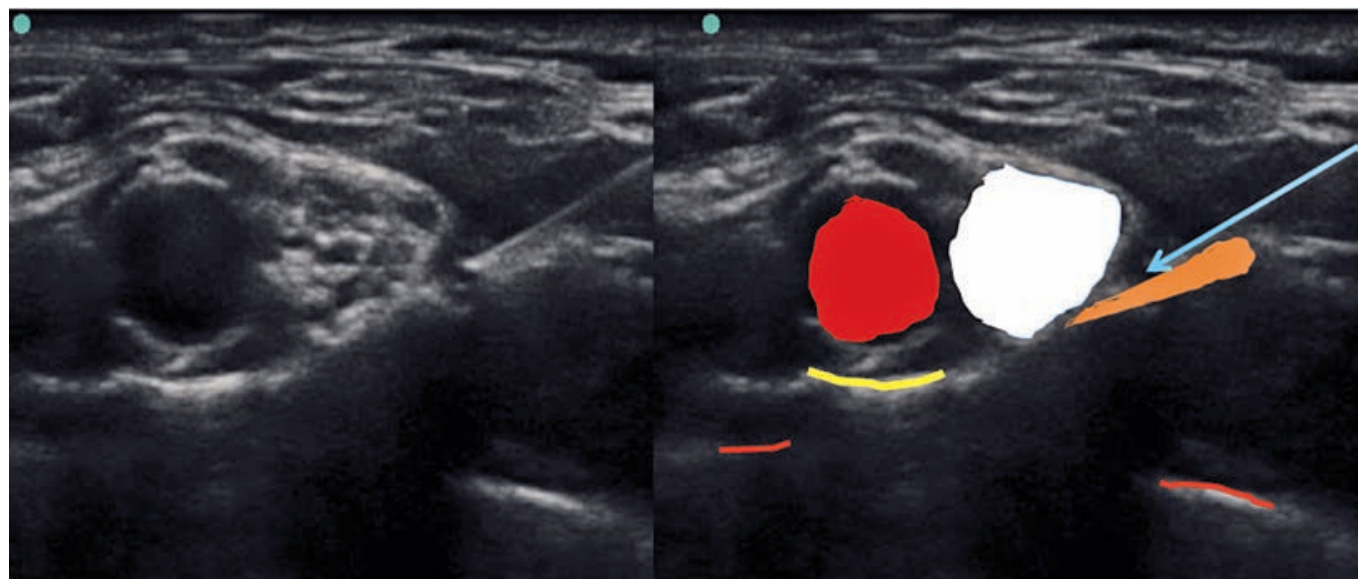

Fig 3. Scout scan of supraclavicular fossa and needle insertion in plane. Red area: subclavian artery, white area: brachial plexus, yellow line: periosteum of first rib, orange line: periosteum of clavicle, red line: pleura, blue arrow: needle.
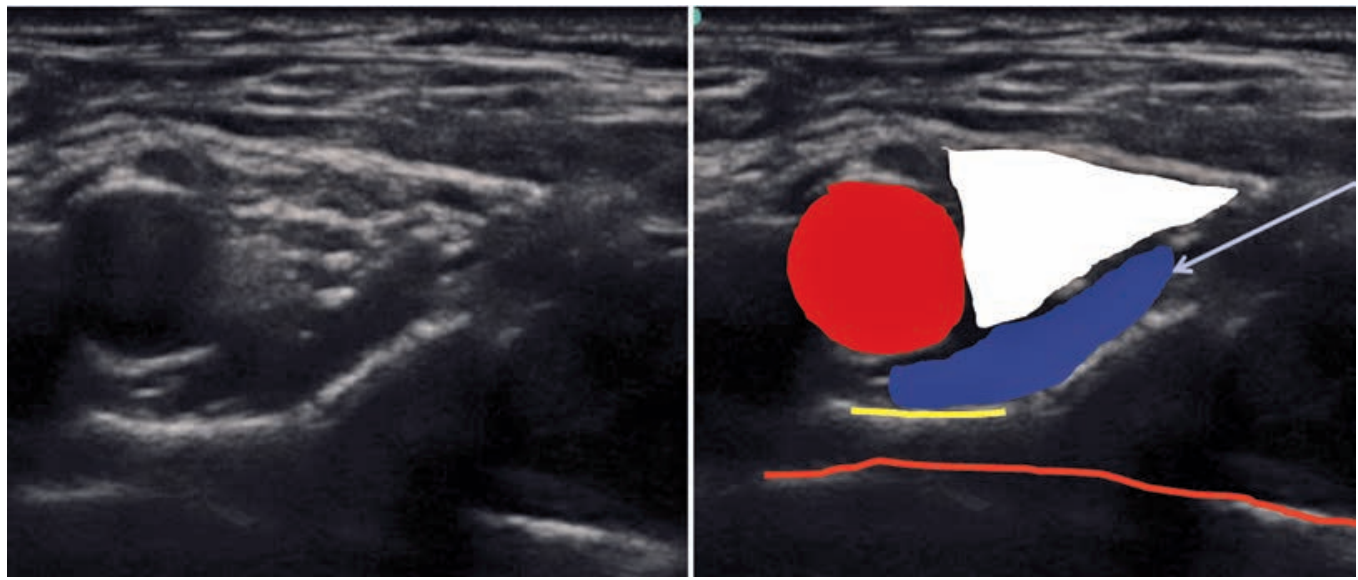

Fig 4. Spread of local anaesthetic solution deep to the plexus. Red area: subclavian artery, white area: brachial plexus, yellow line: periosteum of first rib, red line: pleura, blue arrow: needle, navy area: local anaesthetic. 


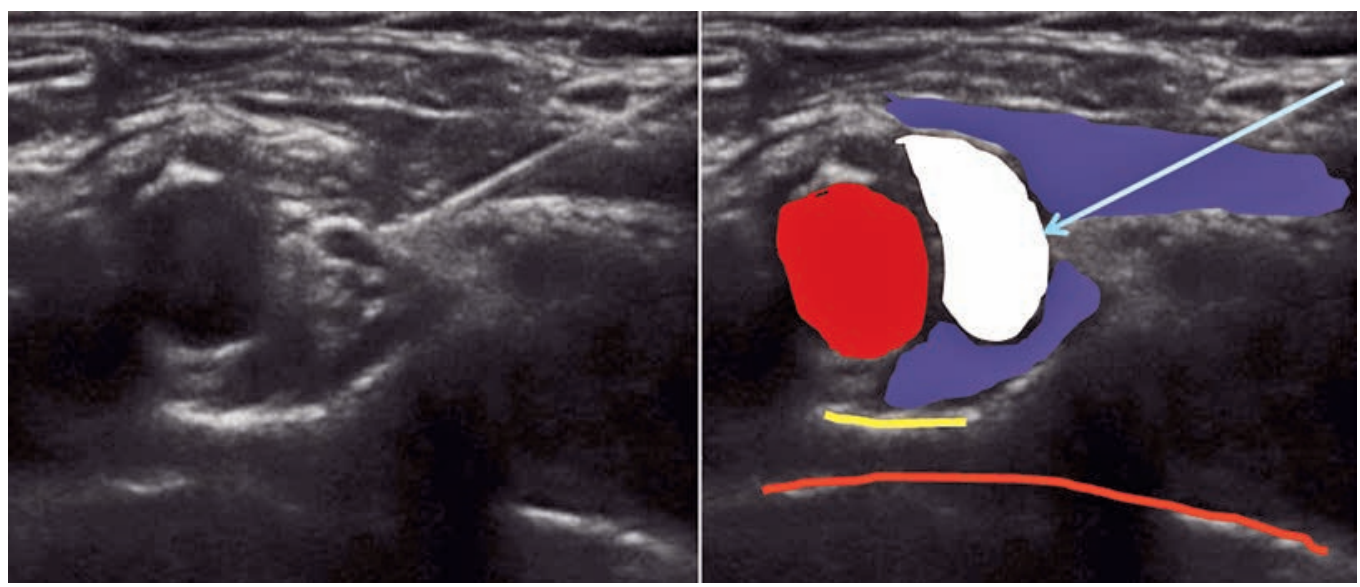

Fig 5. Spread of local anaesthetic superficial to the plexus. Red area: subclavian artery, white area: brachial plexus, yellow line: periosteum of first rib, red line: pleura, blue arrow: needle, navy area: local anaesthetic.

\section{Discussion}

Efficiacy of ultrasound guided supraclavicular blocks:

Arcand et al compared ultrasound guided supraclavicular to ultrasound guided infraclavicular block and demonstrated that surgical anesthesia was similar in both groups although the radial nerve required more frequent supplementation in the infraclavicular group [5]. A retrospective review of ultrasound guided supraclavicular blocks at Toronto Western Hospital revealed a success rate of $94.7 \%$ at first attempt; $2.8 \%$ required local anesthetic supplementation of a single peripheral nerve territory; and $2.6 \%$ received an unplanned general anesthetic. No cases of clinically symptomatic pneumothorax were noted. Complications included symptomatic hemidiaphragmatic paresis $(1 \%)$, Horner syndrome (1\%), unintended vascular punctures $(0.4 \%)$, and transient sensory deficits $(0.4 \%)$ [14]. Koscielniak-Nielsen ZJ et al conducted a study in 120 patients after randomizing them into ultrasound guided supraclavicular and ultrasound guided infraclavicular block. They found similar performance times. Block effectiveness was superior in the infraclavicular group compared to the supraclavicular group, $93 \%$ vs. $78 \%, \mathrm{P}=0.017$ [15]. The supraclavicular group patients had a significantly poorer block of the median and ulnar nerves, but a better block of the axillary nerve. Sensory scores at 10, 20 and $30 \mathrm{~min}$ were not significantly different [15]. Sainz Lopez et al conducted a study in 200 patients who had an ultrasound guided supraclavicluar block for hand and elbow surgery. They concluded that efficacy was $98 \%$ [not requiring general anaesthesia] and no persistent complications were observed [16]. In the study by Kapral et al [11] ultrasound guided supraclavicular block was com- pared to ultrasound guided axillary block. No difference in surgical anaesthesia was found between the two groups of 20 patients, although the musculocutaneous nerve was only blocked in $75 \%$ of the axillary group compared to $100 \%$ in the supraclavicular group.

Ultrasound versus ultrasound plus nerve stimulation technique:

Williams et al examined supraclavicular block with either ultrasound alone or ultrasound with nerve stimulator, and noted faster block performance time with ultrasound alone and no difference in onset or success of sensory and motor block [1]. In a review of 104 patients scheduled for hand surgeries using ultrasound and nerve stimulation by Tsui et al, surgical regional anaesthesia was achieved in $94.2 \%$ of the cases with an onset time of $20.2+/-9.2 \min [17]$.

Paediatric ultrasound guided supraclavicular blocks

There have been numerous reports on the successful use of UGRA in children. De Jose Maria et al compared eighty children between 5-15 years undergoing upper limb surgeries [18]. Forty children were randomly allocated to two groups. One group received ultrasound guided supraclavicular block and the other group received ultrasound guided infraclavicular block. In the supraclavicular brachial plexus blocks, the duration of the sensory block was $6.5+/-2 \mathrm{~h}$ and that of the motor block was $4+/-1 \mathrm{~h}$. Eighty eight \% of blocks achieved surgical anaesthesia in the infraclavicular group without any supplemental analgesia, compared with $95 \%$ in the supraclavicular group. Failures in supraclavicular group were due to insufficient ulnar sensory block. No pneumothorax or 
Horner's syndrome were recorded in either group. The authors concluded that supraclavicular approach of the brachial plexus was less time-consuming than the infraclavicular approach [18].

Potential advantages of ultrasound guided supraclavicular nerve blocks

In general, ultrasound guidance results in local anaesthetic dose reduction. However, in a well conducted study, the minimum volume required for ultrasound guided supraclavicular block in $50 \%$ of patients was 23 $\mathrm{mL}$, and in $95 \%$ of patients was $42 \mathrm{~mL}$ of a local anesthesic mixture (50:50 mixture of lidocaine $2 \%$ and bupivacaine $0.5 \%$ with epinephrine) [20].

This may be a function of the rather 'conservative' approach to supraclavicular block, such as that depicted in figures 4 and 5. Most practitioners would agree that breaching the brachial plexus sheath at supraclavicular level does not constitute intraneural injection. It may result in a closer approximation of the needle and local anaesthetic to the effector site, thus leading to a faster onset and perhaps better success rate [21].

The area inferio-medial to the plexus, postero-lateral to the subclavian artery and superior to the first rib, is commonly referred to as 'the corner pocket' [22]. Despite suggestions that depositing local anaesthetic initially here (similar to figure 4) may be associated with a better ulnar block, one study found an unacceptably high-rate of ulnar sparing using this approach [22].
Our current understanding is that the needle should be redirected as needed to ensure the entire plexus is surrounded by local anesthetic for the best success rate.

Larger number studies are needed to prove that ultrasound guided supraclavicular blocks reduce the risk of complications when compared to traditional methods [23]. The trend so far is towards less complications (table I).

\section{Conclusion}

The recent renewed interest in ultrasound guided supraclavicular blocks may be due to i) easy image acquisition relating to the superficial location of the brachial plexus at this level and ii) identifying the pleura thus minimizing the risk of pneumothorax. Beyond these, all the other attractive features of ultrasound guided peripheral nerve block apply.

\section{References}

1. Williams SR, Chovinard P, Arcand G, et al. Ultrasound guidance speeds execution and improves the quality of supraclavicular block. Anesth Analg 2003; 97: 1518-1523.

2. Neal JM, Gerancher JC, Hebl JR, et al. Upper extremity regional anesthesia: essentials of our current understanding, 2008. Reg Anesth Pain Med 2009; 34: 134-170.

3. Neal JM. Neural blockade in clinical anaesthesia and pain medicine. In: Cousins MJ, Bridenbaugh PO (eds.). Neural Blockade. 3rd ed. Philadelphia: Lippincott; 1998: 318-344.

Table I. Reported complications with ultrasound guided supraclavicular blocks:

\begin{tabular}{|c|c|c|c|c|}
\hline Authors & Study & Groups & Results & Conclusions \\
\hline $\begin{array}{l}\text { Liu SS et } \\
\text { al [19] }\end{array}$ & $\begin{array}{l}\text { Incidence of unintention- } \\
\text { al intraneural injection } \\
\text { and postoperative neu- } \\
\text { rological complications } \\
\text { with US-guided intersca- } \\
\text { lene and supraclavicular } \\
\text { nerve blocks }\end{array}$ & $\begin{array}{l}\mathrm{N}=257 \\
\text { US guided intrasca- } \\
\text { lene }[\mathrm{n}=130] \text { or } \\
\text { supraclavicular block } \\
{[\mathrm{n}=127]} \\
\text { prospective observa- } \\
\text { tional study. }\end{array}$ & $\begin{array}{l}\text { Intraneural injection occurred } \\
\text { in } 42 \text { patients }(17 \% ; 95 \% \text { CI } \\
12-22 \%)\end{array}$ & $\begin{array}{l}\text { Though no patient suffered } \\
\text { from postoperative neurologi- } \\
\text { cal complications, intraneural } \\
\text { injections can occur even with } \\
\text { US guided blocks }\end{array}$ \\
\hline $\begin{array}{l}\text { Bhatia A, } \\
\text { et al [24] }\end{array}$ & $\begin{array}{l}\text { Pneumothorax as a } \\
\text { complication of the US- } \\
\text { guided supraclavicular } \\
\text { approach for brachial } \\
\text { plexus block }\end{array}$ & $\begin{array}{l}\text { Authors describe } \\
\text { the occurrence of } \\
\text { pneumothorax using } \\
\text { US guided supracla- } \\
\text { vicular block (case } \\
\text { report) }\end{array}$ & & $\begin{array}{l}\text { The predisposing operator, } \\
\text { technical, and patient factors as } \\
\text { well as strategies for preventing } \\
\text { this uncommon yet poten- } \\
\text { tially severe complication are } \\
\text { discussed. }\end{array}$ \\
\hline $\begin{array}{l}\text { Perlas A, } \\
\text { et al [14] }\end{array}$ & $\begin{array}{l}\text { US-guided supraclav- } \\
\text { icular block: outcome of } \\
510 \text { consecutive cases. }\end{array}$ & $\begin{array}{l}\mathrm{N}=510 \text { US guided su- } \\
\text { praclavicular blocks } \\
\text { were performed by } \\
47 \text { different operators } \\
\text { at different levels of } \\
\text { training. }\end{array}$ & $\begin{array}{l}\text { Successful anesthesia in } 94.6 \% \\
\text { of patients after a single attempt. } \\
\text { Complications: hemidiaphrag- } \\
\text { matic paresis }(1 \%) \text {, Horner syn- } \\
\text { drome }(1 \%) \text {, unintended vascular } \\
\text { punctures }(0.4 \%) \text {, and transient } \\
\text { sensory deficits }(0.4 \%) \text {. }\end{array}$ & $\begin{array}{l}\text { US-guided supraclavicular } \\
\text { block is associated with a high } \\
\text { rate of successful surgical } \\
\text { anesthesia and a low rate of } \\
\text { complications and thus may } \\
\text { be a safe alternative for both } \\
\text { inpatients and outpatients }\end{array}$ \\
\hline
\end{tabular}


4. Kulenkampff D, Persy MA. Brachial plexus anesthesia: its indications, technique and dangers. Ann Surg 1928; 87:883-891.

5. Arcand G, Williams S, Chouinard P, et al. Ultrasoundguided infraclavicular versus supraclavicular block. Anesth Analg 2005; 101: 886-890.

6. Brown DL, Bridenbaugh LD. The upper extremity: somatic blockade. In: Cousins MJ, Bridenbaugh PO (eds.). Neural Blockade. 3rd ed. Philadelphia: Lippincott; 1998: 345-372.

7. Moorthy SS, Smidt SI, Dierdorf SF, et al. A supraclavicular lateral paravascular approach for brachial plexus regional anesthesia. Anesth Analg 1991; 72: 241-244.

8. Brown DL, Cahill DR, Bridenbaugh DL. Supraclavicular nerve block: anatomic analysis of a method to prevent pneumothorax. Anesth Analg 1993; 76: 530-534.

9. Riegler FX. Brachial plexus block with the nerve stimulator: motor response characteristics at three sites. Reg Anesth 1992;17: 295-299.

10. la Grange P, Foster PA, Pretorius LK. Application of the Doppler ultrasound blood flow detector in supraclavicular brachial plexus block. Br J Anaesth 1978; 50: 965-967.

11. Kapral S, Krafft P, Eibenberger K, et al. Ultrasound-guided supraclavicular approach for regional anesthesia of the brachial plexus. Anesth Analg 1994; 78: 507-13

12. Chan VW, Perlas A, Rawson R, Odukoya O. Ultrasoundguided supraclavicular brachial plexus block. Anesth Analg 2003; 97: 1514-1517.

13. Yang WT, Chui PT, Metreweli C. Anatomy of the normal brachial plexus revealed by sonography and the role of sonographic guidance in anesthesia of the brachial plexus. Am J Roentgenol 1998; 171: 1631-1636.

14. Perlas A, Lobo G, Lo N, et al. Ultrasound-guided supraclavicular block: outcome of 510 consecutive cases. Reg Anesth Pain Med 2009; 34: 171-176.

15. Koscielniak-Nielsen ZJ, Frederiksen BS, Risby Mortensen C. A comparison of ultrasound-guided supraclavicular and infraclavicular blocks for upper extremity surgery. Acta Anaesthesiol Scand 2009; 53: 620-626.

16. Sainz Lopez J, Prat Vallribera A, Segui Pericas M, et al. U1trasound-guided supraclavicular brachial plexus block with small volumes of local anesthetic: technical description and analysis of results [in Spanish]. Rev Esp Anestesiol Reanim 2006; 53: 400-407.

17. Tsui BC, Doyle K, Chu K, Pillay J, Dillane D. Case series: ultrasound-guided supraclavicular block using a curvilinear probe in 104 day-case hand surgery patients. Can J Anaesth 2009; 56: 46-51.

18. De José María B, Banús E, Navarro Egea M, et al. Ultrasound-guided supraclavicular vs infraclavicular brachial plexus blocks in children. Paediatr Anaesth 2008; 18: 838-844.

19. Liu SS, YaDeau JT, Shaw PM, et al. Incidence of unintentional intraneural injection and postoperative neurological complications with ultrasound-guided interscalene and supraclavicular nerve blocks. Anaesthesia 2011; 66: 168-174.

20. Duggan E, El Beheiry H, Perlas A, et al. Minimum effective volume of local anesthetic for ultrasound-guided supraclavicular brachial plexus block. Reg Anesth Pain Med 2009; 34: 215-218.

21. Morfey D, Brull R. Ultrasound-guided supraclavicular block: What is intraneural? Anesthesiology 2010; 112: 250251.

22. Fredrickson MJ, Patel A, Young S, Chinchanwala S. Speed of onset of corner pocket supraclavicular' and infraclavicular ultrasound guided brachial plexus block: a randomised observer-blinded comparison. Anaesthesia 2009; 64: 738-744.

23. Klaastad O, Sauter AR, Dodgson MS. Brachial plexus block with or without ultrasound guidance. Curr Opin Anaesthesiol 2009; 22: 655-660.

24. Bhatia A, Lai J, Chan VW, Brull R. Case report: pneumothorax as a complication of the ultrasound-guided supraclavicular approach for brachial plexus block. Anesth Analg 2010; 111: 817-819. 